again to a convenient position. Operate thus, keeping the surface of separation of liquid and solid at as nearly as possible a constant position of 3 centimetres below the top of the tube, until the surface of separation disappears.

The temperature of tle tube at the place where the surface of separation was seen immediately before disappearance is the critical temperature.

It may be remarked that the changes of bulk produced by the screw and mercury in Andrews' apparatus are, in the method now described, produced by elevations and depressions of temperature in the lower thermal vessel. By proper arrangements these elevations and depressions of temperature may be made as easily, and in some cases as rapidly, as by the turning of a screw. The dispensing with all mechanism and joints, and the simplicity afforded by using the substance to be experimented upon, and no other substance in contact with it, in a hermetically sealed glass vessel, are advantages in the method now described. It is also interesting to remark that in this method we have continuity through the fluid itself all at one equal pressure exceeding the critical pressure, but at different temperatures in different parts, varying continuously from something above the critical temperature at the top of the tube to a temperature below the critical temperature in the lower part of the tube.

The pressure may actually be measured by a proper appliance on the outside of the lower part of the tube to measure its augmentation of volume under applied pressure. If this is to be done, the lower thermal vessel must be applied, not round the bottom of the tube, but round the middle portion of it, leaving, as already described, Io or $20 \mathrm{cms}$. above for observa. ticn of the surface of separation between liquid and vapour, and leaving at the bottom of the tube 20 or $30 \mathrm{cms}$. for the pressure-measuring appliance.

This appliance would be on the same general principle as that adopted by Prof. Tait in his tests of the Challenger thermometers under great pressure (Proceedings, Royal Soc. Edin., 1880); a principle which I have myself used in a form of depth-gauge for deep-sea soundings; in which the pressure is measured, not by the compression of air, but by the flexure or other strain produced in brass or glass or other elastic solid.

\section{ABNORMAL VARIATIONS OF BAROMETRIC PRESSURE IN THE TROPICS, AND THEIR RELATION TO SUN-SPOTS, RAINFALL, AND FAMINES}

IN the first part of his work on the Meteorology of the Bombay Presidency, which was submitted to Government in August, 1875, Mr. Charles Chambers pointed out that the variation of the yearly mean barometric pressure at Bombay shows a periodicity nearly corresponding in duration with the decennial sun-spot period (see "Meteorology of the Bombay Presidency," $\$ 26$, p. 12), and in August, 1878, in a letter to NATURE, vol. xviii. p. 567 , I drew special attention to this relation, pointing out that the observations of the winter and summer half-years, separately as well as conjointly, show that the pressure is low when the sunspot area is great, and vice zersâ, but that the pressure curve lags behind the sun-spot curve.

In November of the same year the eminent physicist, the late Mr. John Allan Broun, regarding the relation thus established between the variations of barometric pressure and sun-spots as one of very great importance, in that it gave a probability to the existence of similar laws in the variations of other meteorological elements which he believed was previously wanting, communicated to the same periodical (NATURE, vol. xix. p. 6) an article in which he showed, from the observations recorded at Singapore, Trevandrum, Madras, and Bombay, that the years of greatest and least mean barometric pressure are probably the same for all India, and from this he inferred that the relation to the decennial sun-spot period found for Bombay holds for all India.

In December, 1878, Mr. S. A. Hill supplemented and confirmed Mr. Broun's communication by giving similar data for Calcutta (NATURE, vol. xix. p. 432).

In May, 1879, Mr. E. D. Archibald communicated to NATURE, vol. xx. p. 28, the fact (brought to his notice by Mr. S. A. Hill) that at St. Petersburg the mean annual barometric pressure is high when the sun-spots are numerous, low when they are few, but that the pressure epochs lag behind the sun-spot epochs.
In December of the same year Mr. Blanford presented to the Asiatic Society of Bengal a paper (Fournal of the Asiatic Society of Bengal, vol. xlix. part ii. 188o, p. 70) in which it was shown that the barometric observations recorded at Batavia from 1866 to 1878 , at Akyab, Chittagong, and Darjeeling from 1867 to 1878 , at Port Blair from 1868 to 1878 , and at Singapore from 1869 to 1878 , afford more or less confirmation of the results previously obtained for other stations in India. ${ }^{x}$ And in the same paper Mr. Blanford brought forward the observations recorded at the Kussian observatories at Ekaterinburg, Slatoust, Bogolowsk, and Barnaul from 1847 to 1877 , and showed that at the two former stations during the whole period, and at the two latter during the first half of it, the barometric variations were similar to those previously obtained by Mr. Hill for St. Petersburg.

In a subsequent letter to NATURE, published in March, 1880 , Mr. Blanford discussed the same observations in greater detail, dealing with the summer and winter observations separately, as well as conjointly, and showed that the decennial variation of the barometric pressure found for St. Petersburg was exhibited only by the observations of the winter months. He also obtained similar results for Ekaterinburg and Barnaul, but he appears to have overlooked the very important facts that the range of the winter curves rapidly decreases in passing from St. Petersburg, through Ekaterinburg to Barnauland, that the summer curves for the two latter stations are, on the whole, of the same character as the summer curves of the Indian stations, as may be seen by comparing the dotted curves for Ekaterinburg and Barnaul, given in NATURE, vol. xxi. p. 48 , with the summer curve for Bombay, given in vol. xviii. p. 568 of the same periodical. He also showed that the barometric curves for Batavia, Singapore, and Port Blair were, as at other Indian stations, of the same character both in winter and summer.

In 1873 and 1874 (see British Association Reports for those years) Mr. Meldrum showed that there was strong evidence of a connection between sun-spots and rainfall, and he has recently fsee Monthly Notice of the Meteorological Society of Mauritius for December 1878) put this question beyond all reasonable doubt by showing that the mean yearly rainfall of Great Britain, the continent of Europe, America, India, and the Southern Hemisphere, varies in the same way as the sun-spots, being on the average great when they are numerous, small when they are few.

In my "Brief Sketch of the Meteorology of the Bombay Presidency" 2 in 1876 , I pointed out that the abnormal variations of the monthly mean barometric pressure in that year were mainly variations in the intensity of the usual seasonal movements, although at least some portion of the variations influenced a wider area than the Indian monsoon region, and in the Sketch for 1877 I attributed the uniformly high barometric pressure and the deficient rainfall of that year to a weak development of the equatorial belt of minimum pressure, probably induced by a diminution of the solar heat.

In the Report on the Meteorology of India in I877 Mr. Eliot showed that the high pressure of that year was a characteristic of the whole Indian area and also of Australia.

In my meteorological sketch for 1878 I showed that the abnormal barometric movements observed at $\mathrm{Zi}-\mathrm{ka}$ wei in China and at Manilla in 1878 were similar to those recorded in Western India ; that the latter largely influenced the rainfall of the Bombay Presidency; and that in former years of deficient rainfall at Bombay the barometer had been relatively high, not only at Bombay, but also at Mauritius and Batavia.

In the paper (Fournal of the Asiatic Society of Bengal, vol. xlix. part ii., 1880, p. 70) already quoted, Mr. Blanford has confirmed the fact that the excessive pressure observed in the Indian area in the years 1876 to 1878 extended to China and Australia, and he has also shown that it affected Western Siberia also.

In my sketch for the year I879 I have shown that these uniform variations of barometric pressure are accompanied by a nearly uniform variation of the percentage rainfall of all portions

I During the first half of these periods the results for Singapore, Akyab, Chittagong, and Darjeeling differ so much from each other and from the remarkably accordant results obtained from the more widely separated stations of Bombay, Calcutta, Port Blair, and Batavia as to suggest that the former are of doubtful validity during the earlier years.

2 These sketches are submitted annually to Government in August of the 2 These sketches are submitted annually to Government in August of the
year following that to which they refer. See notices in NATURE, vol. xviii. pp. r99 and 6rg, vol. xxi. p. 384 . The sketch for 1879 , containing some 
of the Bombay Presidency, and that the proportionate increase or decrease of the abnormal rainfall, corresponding to a fall or rise in the abnormal pressure of a tenth of an inch of mercury, amounts to more than one hundred per cent. of the normall fall; but that the variations of the ordinary monsoon gradients produce very different effects on the rainfall of different districts, depending on the geographical peculiarities of the particular locality.

From all these facts it is clear that there is some intimate relation between the variations of sun-spots, barometric pressure, and rainfall; and as famines in general are induced by a deficiency of rain, it is probable that they also may be added to the above list of connected phenomena. What is required in order to gain an insight into the causal relation of these variations is that they should each and all be studied in greater detail than has hitherto been attempted. Accordingly I commenced, more than a year ago, a detailed investigation into the nature of the abnormal variations of barometric pressure, and have been led to the discovery of some new facts which appear to me to be of sufficient importance to render it desirable that they should be published in anticipation of the theoretical conclusions deducible therefrom.

Commencing with the daily abnormal barometric variations observed at several stations in Western India, it was soon found that as the time over which an abnormal barometric fluctuation extended became longer and longer, the range of the fluctuation became more and more uniform at the various stations, thus leading to the conclusion that the abnormal variations of long

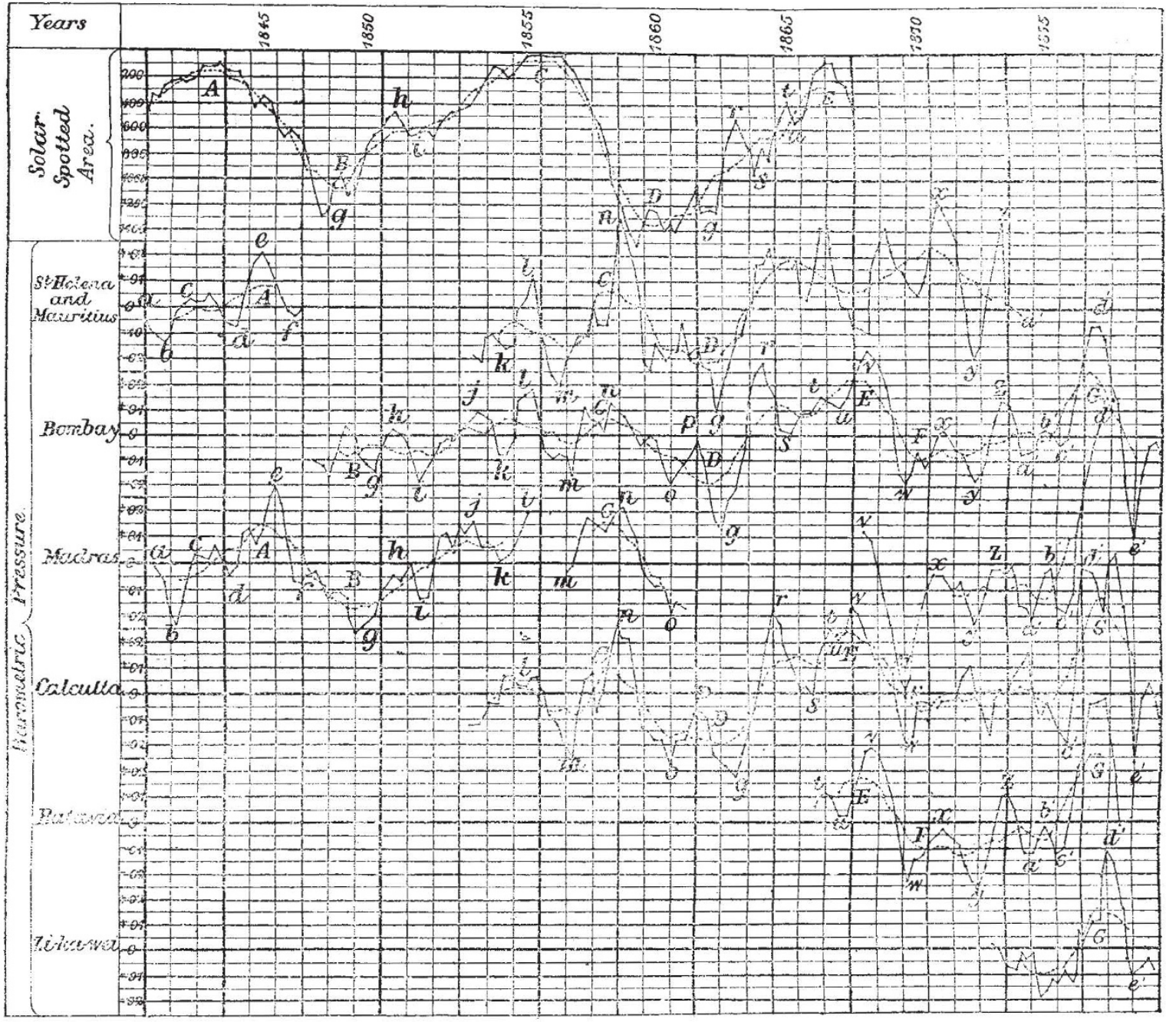

duration affect a very wide area. To test this inference it became necessary to compare the observations recorded at Bombay with those of some distant tropical station. Batavia was chosen, and on curving the daily observations side by side with those of Bombay, the degree of accordance between them was found to be truly surprising, considering how far the two stations are apart. The next step was to compare the monthly abnormal variations of these two stations, and finding that they presented many similar features, as well as some differences, to smooth the variations by taking three-monthly means. The degree of accordance was now found to be still greater, many of the discordances having been eiliminated in the process of smoothing; but as some differences were still observable the process was re peated, giving nine-monthly means of abnormal pressure corre- sponding to the middle of the months January, April, July, and October of each year. The curves obtained in this way for Bombay and Batavia were then found to be almost identical in form, but with this very remarkable difference: the curve for Batavia was seen to lag very persistently about one month bchind the Bombay curve. Similar results were then worked out from all the available data for the following tropical stations: St. Helena, Mauritius, Madras, Calcutta, and Zi-ka-wei, and for comparison with them the monthly sun-spot areas ${ }^{1}$ were treated in exactly the same manner. The results are given in the fol lowing table, and graphically represented by the continuous curves on the annexed plate :-

I Taken from the paper by Messrs. De La Rue, Stewart, and Loewy, published in the Philosophical Transactions for 1870, p. 122. 


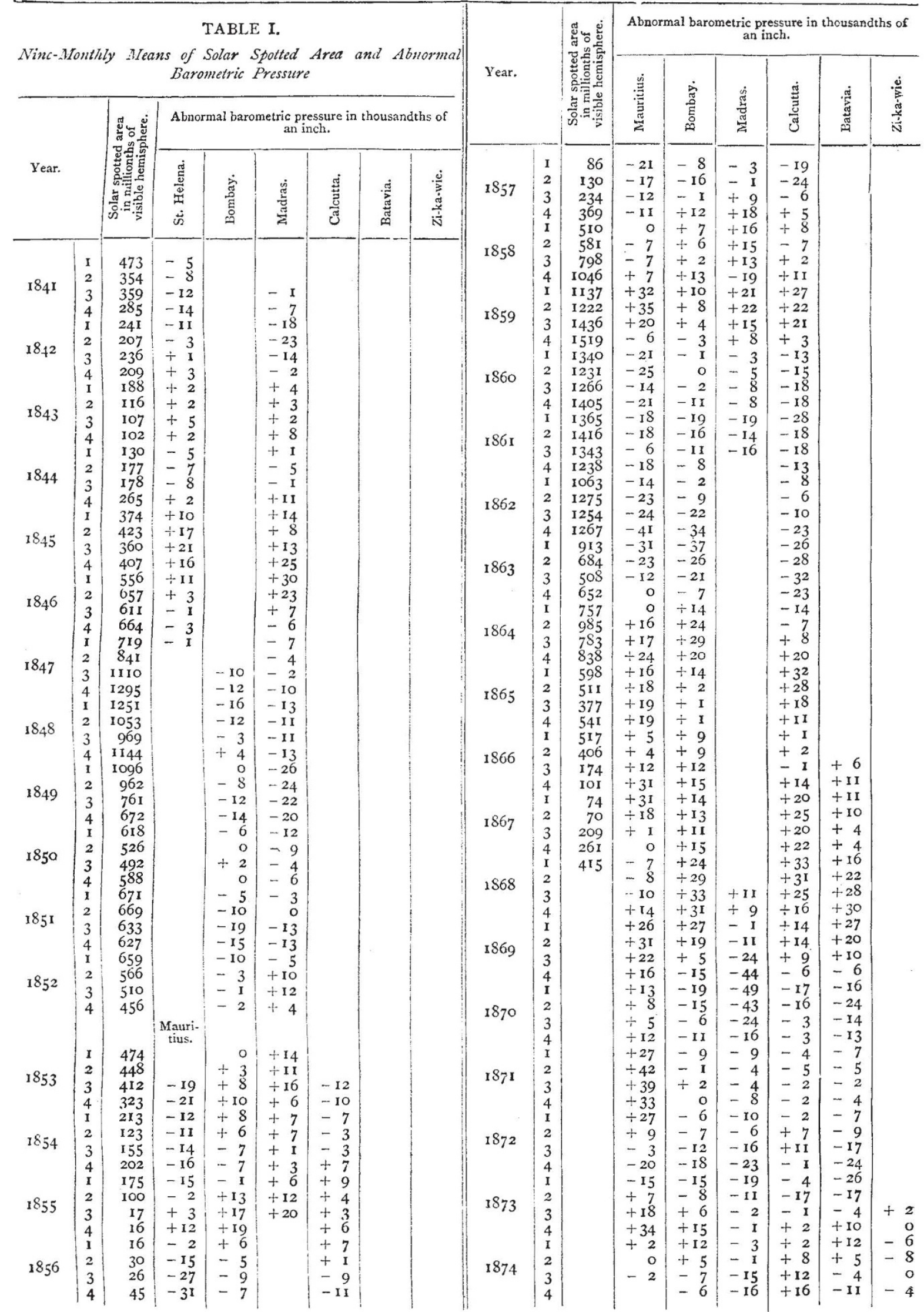


TABLE I. (Continued)-

\begin{tabular}{|c|c|c|c|c|c|c|c|c|}
\hline \multirow[b]{2}{*}{ Year. } & & \multirow{2}{*}{ 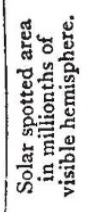 } & \multicolumn{6}{|c|}{$\begin{array}{l}\text { Abnormal barometric pressure in thousandths of } \\
\text { an inch. }\end{array}$} \\
\hline & & & $\begin{array}{l}\text { 总 } \\
\text { 总 } \\
\text { 营 }\end{array}$ & $\begin{array}{l}\text { 离 } \\
\text { 莒 } \\
\text { œ }\end{array}$ & 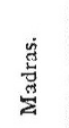 & 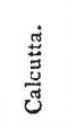 & 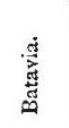 & 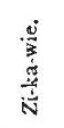 \\
\hline \multirow{5}{*}{1875} & I & & & -5 & -22 & +2 & $-I I$ & \\
\hline & 2 & & & $+x$ & - II & -10 & -7 & -18 \\
\hline & 3 & & & +2 & -4 & -3 & $-I$ & -16 \\
\hline & 4 & & & $+\mathbf{I}$ & $-I$ & -9 & -5 & -12 \\
\hline & $\begin{array}{l}I \\
2\end{array}$ & & & $\begin{array}{l}-3 \\
-\mathbf{r}\end{array}$ & $\begin{array}{l}-16 \\
-18\end{array}$ & $\begin{array}{l}-14 \\
-19\end{array}$ & $\begin{array}{l}-11 \\
-I 0\end{array}$ & $\begin{array}{l}-13 \\
-8\end{array}$ \\
\hline \multirow{3}{*}{1876} & 3 & & & +9 & -13 & -3 & $+I$ & -12 \\
\hline & 4 & & & +21 & +12 & +27 & +22 & +8 \\
\hline & I & & & +29 & +30 & +49 & +28 & +4 \\
\hline \multirow{3}{*}{1877} & 2 & & & +43 & +46 & $+4^{8}$ & +46 & $+I I$ \\
\hline & 3 & & & +43 & +55 & +43 & +47 & +12 \\
\hline & $\begin{array}{l}4 \\
\text { I }\end{array}$ & & & $\begin{array}{l}+38 \\
+24\end{array}$ & & $\begin{array}{l}+32 \\
+51\end{array}$ & $\begin{array}{r}+49 \\
+34\end{array}$ & $\begin{array}{l}+29 \\
+39\end{array}$ \\
\hline \multirow{3}{*}{ x 878} & 2 & & & +13 & & +55 & +17 & +34 \\
\hline & 3 & & & $\begin{array}{l}-15 \\
-33\end{array}$ & & +33 & $-I$ & +16 \\
\hline & I & & & $\begin{array}{l}-33 \\
-40\end{array}$ & & -26 & & $\begin{array}{l}-4 \\
-10\end{array}$ \\
\hline 879 & 2 & & & $-\mathrm{I} 5$ & & -2 & & -7 \\
\hline & 4 & & & $\begin{array}{l}-4 \\
-1\end{array}$ & & $\begin{array}{l}+4 \\
-2\end{array}$ & & -8 \\
\hline 1880 & I & & & -8 & & -14 & & \\
\hline
\end{tabular}

Comparison of Abnormal Barometric Movements at Different Stations. - The general resemblance of all these curves to each other is very remarkable; indeed if the Mauritius curve for the years 1867 and 1868 be excluded, there is scarcely a single prominent feature in any one of the curves which is not reproduced in the others. To show this the corresponding points of the different curves have been marked with the same small letters. It will be seen, however, that there is strong evidence of a want of exact simultaneity in the barometric movements at different stations, and that as a rule the changes take place at the more westerly stations several months earlier than at the more easterly ones. This is particularly noticeable in the curves for St. Helena and Madras from I84I to I846, when the latter sometimes lagged behind the former by as much as six months; in those for Mauritius and Calcutta from 1855 to 1866 , when the latter persistently lagged several months behind the former ; in those for Bombay and Calcutta from 1862 to 1866 , when the difference in time often amounted to upwards of six months; in those for Bombay and Batavia from 1867 to 1878 , when (as already remarked) the latter lagged behind the former at an average interval of about one month; and in those for Bombay and Ti-ka-wei from 1876 to 1878 , when the latter lagged upwards of six months behind the former. It appears then that these long atmospheric waves (if such they may be called) travel at a very slow and variable rate round the earth from west to east, like the cyclones of the extra tropical latiludes.

Bombay

( $T$ o be continuted.)

Fred. Chambers

DR. SIEMENS'S NEW CURE FOR SMOKE

F ROM among a number of letters which have been sent us on this subject we have selected the following for publication ; to these Dr. Siemens has been good enough to append some important remarks.

In NATURE, vol. xxiii. p. 25, I read with interest an article by Dr. Siemens describing an ingenious gas and coke fire which he suggests as a cure for the smoke nuisance. But although the darkening of the atmosphere or fog will certainly be prevented by its use, I am afraid the gases from the coke, especially the carbonic oxide, will make the fogs at least as poisonous and injurious to health as the open coal fires at present in use.

In these circumstances a description of an "Asbestos gas fire" free from this objection, which we have had in use in our smoking room for the last three years, and which, after a few alterations, has proved perfectly satisfactory, may perhaps interest your readers.
A $\frac{1}{4}$-inch gas-pipe furnished with four Bunsen burners is laid on the hearthstone under the grate and parallel to the ribs, so arranged that the tops of the burners (which are made elliptical to pass through the bars) are flush with the upper surface of the grate, and two inches back from the line of the ribs. The fireplace is loosely filled with a preparation of asbestos in pieces about the size of a hen's egg.

This fire not only evolves a large amount of heat, but has a very cheerful appearance, similar to that of a bright coke fire, and to insure this it is essential that the burners should be placed close to the ribs, as stated above, and not in the centre of the grate. If this is not attended to the asbestos in the centre of the fire will be raised to a high temperature, but will not be sufficient to heat those portions in front, which will then not only be of no use as radiators in themselves, but act as screens to the light and heat generated in the centre. I suspect this was the cause of the failure of Dr. Siemens' pumice gas fire.

The cost of maintaining this fire is simply that of the amount of gas burned, as the asbestos is not consumed, and its prime cost is trifling. I have only further to add that there is not the slightest trace of fumes or smell from the fire two minutes after it is lighted.

Edinburgh, November 15

DR. SIEMENS has described in your pages the form of cokegas grate which he has fitted in his own house. As I had fitted a similar arrangement in this house before Dr. Siemens' letter appeared in the Times of November 3 , and as it is simpler than Dr. Siemens' and succeeds even beyond my expectation, I send you a drawing and description of it. It varies, of course, according to the shape of the grate in which it is fitted; but for the sake of comparison I have copied Dr. Siemens' grate, and drawn my arrangement as fitted into it.

Instead of Dr. Siemens' arrangement for withdrawing the heat from the back of the fire and bringing it to the front, I merely line the whole grate-sides, back, and bottom-with fire-bricks. This obviates the necessity for the close-fitting ash-pan described by Dr. Siemens, which would be rather expensive to fit. I make the fire-brick in the bottom of the grate slope towards the front, and leave a space of one inch between the front of it and the perforated gaspipe down which space the ashes fall on to the hearth.

If my grate is not quite so economical in working as Dr. Siemens', it is very near it, and the first cost of fitting is considerably less. In fact, as most grates are lined with fire-brick at back and sides, nothing has to be done but fit a wedge-shaped fire-brick into the bottom, a half-inch iron gaspipe, perforated with holes in front, and connect it with the gas service, all of which can generally be done for a few shillings.

The saving of kindling-wood and of chimney-sweeping would pay for it in a year. In Dr. Siemèns' grate the copper must cost about $\mathrm{r} l$. A grate fitted with this arrangement looks exactly the same as an ordinary grate, and there is nothing to prevent ordinary coal being burnt in it-in fact coal can be burnt in it with much less smoke than in an ordinary grate by turning on the gas for a few minutes when fresh coal is put on, when the dense black smoke emitted by the new coal is completely burnt up in the gas-flame. To people who object that a gas grate must produce a bad smell in the room I can only say, "Come and see." They will find that we have three grates with this arrangement in constant use in these chambers, and that they produce no smell and make a very pleasant fire. Any person who takes an interest in the subject is quite welcome to come in and look at them at any time.

Adelphi Chambers, 7, John Street, Adelphi

HAYING been experimenting for some years in the direction referred to by Dr. Siemens in NATURE, vol. xxiii. p. 25, I must beg to differ with him most seriously in some of his conclusions. The gas-fire with coke which he describes has, so far as our experience goes, several practical objections which prevent its use in the place of an ordinary gas fire, whilst when compared with a good coal fire it fails seriously.

First, with regard to the objections to Dr. Siemens' fire. It requires about half an hour to become anything like warm, as against ten to fifteen minutes with a well-lighted coal fire. Second, it makes as much or more dust and dirt than a good coal fire. Third, the grate requires as much cleaning and care as with coal.

I am not surprised at the economy, comparing the coal fire as shown with gas and coke, but if the result had been taken in 